\title{
Factors Affecting Management of Epilepsy Amongest Epileptic Clients Receiving Services at Serere Health Centre IV Serere District.
}

\author{
Olinga Micheal Albert ${ }^{a}$ \\ a Soroti School of Registered Comprehensive Nursing
}

\begin{abstract}
\end{abstract}

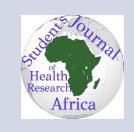

Background:

Epilepsy is a neurological condition, which affects the nervous system. It is usually diagnosed after a person has had the least two sutures that were not caused by some known medical condition like; Alcohol withdrawal, extremely low blood sugar, heart problems, or some other medical condition. Epilepsy can also be diagnosed after a seizure if a patient has a condition that places them at risk for having another seizure.

Methodology:

The study had both quantitative and qualitative methods of data collection like; data collection tools. The data was collected from 30 respondents who were especially epileptic clients in the catchment area of the whole Centre. Data aggregation, entry, and analysis were done using the Micro-soft excel tool.

Results:

The study showed that the majority of the respondents were not married (66.7\%), majority of the respondents were below the age of 19 years (40\%), also most of the respondents were not educated (40\%), (10\%) and (23.3\%) blamed epilepsy on witchcraft and curse from God, (93.7\%) have ever missed clinic day, (55\%) had come alone to the clinic.

Recommendation :

Concerned authority and well-wishers are called upon to take up the findings or conduct their study related to these problems to see the way forward.

Conclusion: ${ }^{a}$

Drug adherence, discrimination, low family social support, were the major factors affecting the management of epilepsy. These challenges would majorly be resolved through health education and counseling of the entire communities.

${ }^{a}$ submitted: 15th/9/2021 accepted:
25th/9/2021 email: Omichealal-
bert@gmail.com

\section{Background.}

Epilepsy is a neurological condition, which affects the nervous system (Inside, 2013). According to (patty, 2013), Epilepsy is also known as a seizure disorder. It is usually diagnosed after a person has had at least two seizures that were not caused by some known medical condition like alcohol withdrawal, extremely low blood sugar, heart problems, or some other medical condition (patty, 2013), . Epilepsy can also be diagnosed after one seizure if a patient has a condition that places them at risk for having another seizure. 
Epilepsy Foundation of American, (2000) defines epilepsy as a physical condition that occurs when there is a sudden, brief change in how the brain works. When the brain cells are not working properly, a person's consciousness, movement, or actions may be altered for a short time.

These physical changes are called epileptic seizures. Epilepsy is therefore sometimes called a seizure disorder.

For both the sufferers and non-sufferers, epilepsy arouses fear, anger, despair, and other strong negative emotions. Ignorance of what it is and what can be done seems to be at the root of the problem. To health workers, poor understanding is partly due to the diverse definitions, with much emphasis put on convulsions that often cause the exclusion of other aspects. However, motor function is only one aspect of brain function and epileptic seizures do not necessarily need to be accompanied by convulsions.

According to Odaga et al., (2008), like many other mental illnesses, epilepsy is more prevalent than is commonly acknowledged. Moreover, its social and economic burden is excessive for the individual, family, health system, and country at large. (Odaga, 2008) People with epilepsy have a low quality of life and productivity. They and their families are stigmatized and discriminated against. (Odaga, 2008).

Although the symptoms listed below are not necessarily indicators of epilepsy, it is wise to consult a doctor if an individual or family member experiences one or more of;

- "Blackouts", or periods of confused memory;

- Episodes of staring or unexplained periods of unresponsiveness;

- Involuntary movement of arms and legs;

- "Fainting spells" with incontinence or followed by excessive fatigue; or

- Odd sounds, distorted perceptions, the episodic feeling of fear that cannot be explained, (Epilepsy Foundation of America 2004).

Willmore et al., (2007) says epilepsy in elderly patients is a growing worldwide challenge; as the population ages, the prevalence of epilepsy increases. Management of epilepsy in elderly patients requires an understanding of their unique medical and pharmacological characteristics. Accurate assessment of seizures, thorough neurological assessment to define etiology, and evaluation of concomitant illness and living situations are neces- sary for comprehensive treatment, planning, and informed management.

Treatment modalities over the cases have progressively changed with marked improvement in clinical diagnostic measures and management. However, the deinstitutionalization management process for mentally ill people which demonstrates good outcomes has also met its shortcomings related to the society-drug relations with patients' compliance and a health institution problem, (Berkov R, 2007).

Reuber (2007) said that even with the arrival of improved treatment modalities at least $68.7 \%$ with epilepsy had prolonged attacks, $60.6 \%$ with ongoing seizures, and $57.9 \%$ with major seizures had access to specialist advice at the hospital. They noted that utilization of investigative services and lacks of access to specialists' advice were indications of poor seizure control. This poses a danger to the PLWE in terms of sudden unexpected death which accounts for $10 \%$ of global incidences resulting from asphyxia and operation on disability.

Odaga et al., (2008), during a study he conducted in the districts of Nebbi and Arua stated that "the burdens produced by epilepsy go beyond the sheer number of individuals affected by the condition. People with epilepsy have a lower quality of life and productivity than people with other chronic illnesses. In many developing countries epileptics and their families are stigmatized and discriminated against. (Odoga et al., 2008). Epilepsy threatens the aspirations of the entire family, not just of the individuals with the disease". Therefore, epilepsy is a significant public health and socioeconomic burden, requiring urgent action.

\section{METHODOLOGY Study design and rationale}

The study design used was a descriptive study design which involved the use of a questionnaire and a focused group discussion guide. This design was selected because it was considered to be simple and would not require vigorous analysis. All the questions relevant to the study would be in the questionnaire and the focused group discussion guide. This enhanced data collection, analysis, and presentation, as well as interpretation of the findings.

\section{Study setting and rationale}


This study was carried out in the mental health clinic of SHC IV. The health center is located in Serere town council, Serere District, located in the eastern region of Uganda. The health center had an outpatient department, where the mental health clinic was conducted once monthly on a Thursday. It also had four admission wards, an operating theatre, and a laboratory. On a clinic day they received approximately 80 clients, this number was inclusive of epileptic clients who usually made up the highest numbers.

The study area was chosen because the health center was easily accessible, given the limited time that was availed for the study. The health center had a mental health clinic where a representative category of patients from various locations assemble every last Thursday of the month to collect drugs; this made it easy for the researcher to collect data. No similar study had been conducted at the health facility before

\section{Study population}

The study covered both males and female respondents who usually received services at SHC IV.

\section{Sample size determination}

The sample size consisted of thirty (30) respondents, this was based on the time that was allocated for the research and finances that were available. This number of respondents had been chosen because it was relatively cheap to handle, data was collected at the shortest time that was possible and the data collected was free of bias and bore an accurate reflection of the situation under study among the entire population.

\section{Sampling procedure}

The systematic sampling method was used where papers bearing numbers 1-50 were randomly distributed, the individuals who will pick papers bearing numbers 1-30, were the ones who did the interview.

\section{Inclusion criteria}

Only individuals aged 14 years and above were allowed to actively participate, for those below 14 years, their caretakers were the ones who did the interview.

\section{Definition of variables}

Independent variables were factors affecting the management of epilepsy and socio-demographic factors like age, marital status, religion, and level of education.
Dependent variables were the suggested measures to improve the management of epilepsy.

\section{Research instruments}

The researcher used semi-structured questionnaires (one for the respondents and the other for the health workers) for data collection. The questionnaires consisted of open-ended and closedended questions.

The questionnaires were used because they were cheap to administer, they would cover a wide number of respondents in a short time, they were economical and did not involve social interaction with those respondents that were not able to read and write.

\section{Data collection procedure}

Data were collected using self-administered questionnaires with the aid of a translator in instances where individuals were not able to read or write and through documents analysis of records that were related to the research topic.

\section{Data management}

The data was tally coded, edited in the field, and presented in form of frequency tables, statements, and figures.

\section{Data analysis}

The data was analyzed manually by physical counting and coding of the questionnaires. The results were then presented in frequency tables and figures and were later analyzed using percentages.

\section{Ethical considerations}

The following ethical considerations were observed by the researcher;

1. Respondents were assured that information they were to give was to be treated and kept confidential.

2. Respondents were required to sign a consent form as a pre-requisite to entering the study.

3. The researcher had to establish rapport with the respondents during the time of data collection.

4. All professional Nursing ethics, Cultural and Religious Beliefs of the clients were observed during the study.

\section{Limitation of the study}

The researcher faced the following challenges during the study.

1. Limited up to date (the year 2003 to date) books to refer to in the nearby libraries, most of which did not even have literature on the study topic. This forced the researcher to rely most of the time on the internet. 
2. There was no special time provided for research on the school timetable. Other school programs continued and made it difficult to carry on the study with ease; the researcher conditionally learned self-programming to submit the report in time.

3. There were constraints in financing the research in terms of internet, typing, printing, and photocopying, the researcher, therefore, had to limit himself on the number of respondents, and the amount of data presented.

\section{Dissemination of results}

The research findings were distributed as follows;

1. The Uganda Nurses and midwives examination board, for the award of a diploma in comprehensive nursing.

2. Serere district health office, for awareness of the factors affecting management of epilepsy and ways to improve its management.

3. Soroti School of the comprehensive nursing school library

\section{RESULTS AND DATA ANALYSIS Description of the sample tables and figures}

The researcher was interested in the biographical information of the respondents because he generally believed management of epilepsy varies greatly among age groups, sex, marital status, region, education level, and occupation.

In the first instance, the researcher was interested in establishing the age distribution of the respondents; the results were as in Table 1 below.

Showing age distribution of the respondents $(n=30)$

Majority $40 \%$ of the respondents were in the age group of less than 19 years, followed by $30 \%$ in the age group 20-29.

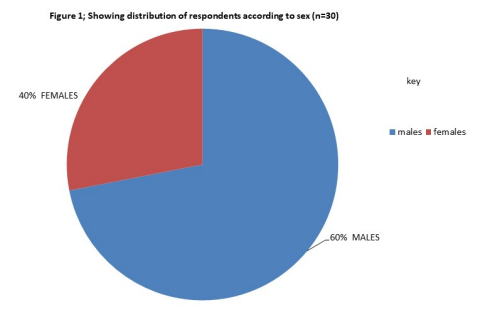

Majority, $60 \%$ of the responssdents were males while $40 \%$ were females.
Majority of the respondents, $56.7 \%$ were Iteso, $10 \%$ and $33.3 \%$ were Kumam and others respectively.

Majority, $66.7 \%$ of the respondents were single, followed by $16.7 \%$ who were married.

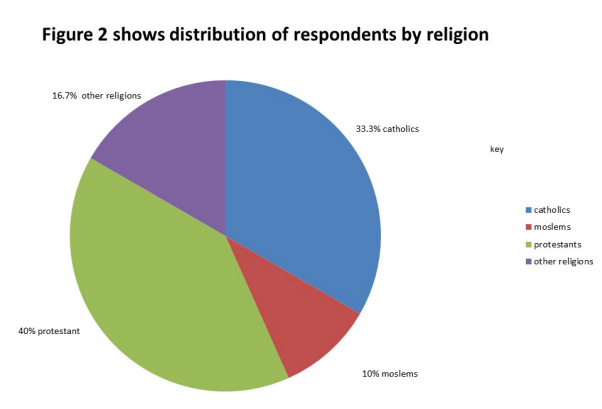

The respondents were Protestants $40 \%$ mostly, 33.3\% were Catholics.

Non educated (40\%) mostly, 33.3\% attended only primary.

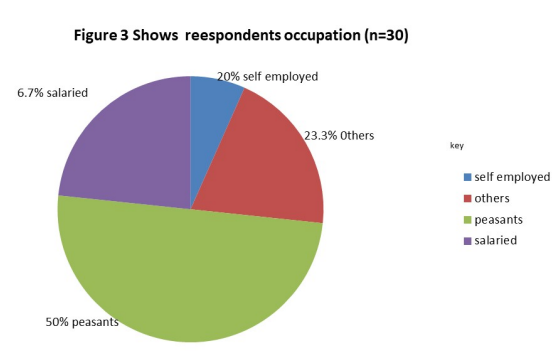

$50 \%$ of the respondents were peasants while $23.3 \%$ had other forms of employment.

Factors affecting management of Epilepsy

Figure 4; showing whether respondents got their AEDs regularly

Majority of the respondents, $66.7 \%$ got their AEDs regularly, while $33.3 \%$ did not.

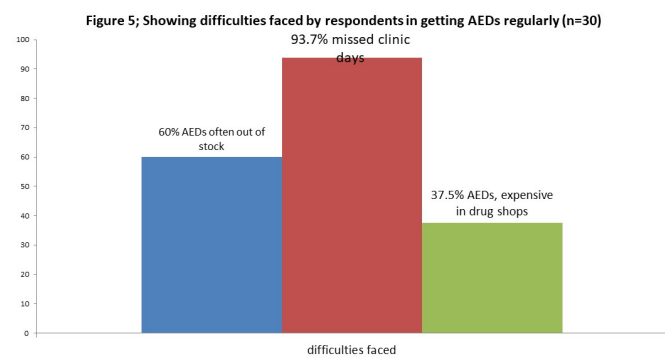


Table 1. Showing age distribution of the respondents

\begin{tabular}{lll}
\hline Age group (years) & Frequency & Percentage (\%) \\
Less than 19 & 12 & 40 \\
$20-29$ & 9 & 30 \\
$30-39$ & 5 & 16.6 \\
$40-49$ & 2 & 6.7 \\
50 and above & 2 & 6.7 \\
Total & $\mathbf{3 0}$ & $\mathbf{1 0 0}$ \\
\hline
\end{tabular}

Table 2. Showing distribution of respondents according to tribe $(n=30)$

\begin{tabular}{lll}
\hline Tribe & Frequency & Percentage (\%) \\
Iteso & 17 & 56.7 \\
Kumam & 3 & 10 \\
others & 10 & 33.3 \\
Total & $\mathbf{3 0}$ & $\mathbf{1 0 0}$ \\
\hline
\end{tabular}

Table 3. shows distribution of respondents according to their marital status $(n=30)$.

\begin{tabular}{lll}
\hline Marital status & frequency & Percentage (\%) \\
Single & 20 & 66.7 \\
Divorced & 4 & 13.3 \\
Widowed & 1 & 3.3 \\
Married & 5 & 16.7 \\
Total & $\mathbf{3 0}$ & $\mathbf{1 0 0}$ \\
\hline
\end{tabular}

Table 4. Shows education levels of the respondents. $(n=30)$

\begin{tabular}{lll}
\hline Education level & frequency & Percentage (\%) \\
No education & 12 & 40 \\
Primary & 10 & 33.3 \\
Secondary & 6 & 20 \\
Tertiary & 2 & 6.7 \\
Total & $\mathbf{3 0}$ & $\mathbf{1 0 0}$ \\
\hline
\end{tabular}

The majority ( $60 \%$ ) of the respondents said AEDs were often out of stock, 93.7\% missed epilepsy clinic days, and $37.5 \%$ said that AEDs were expensive in drug shops.

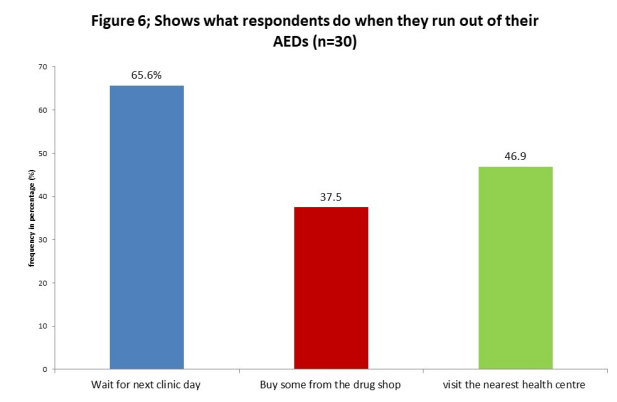




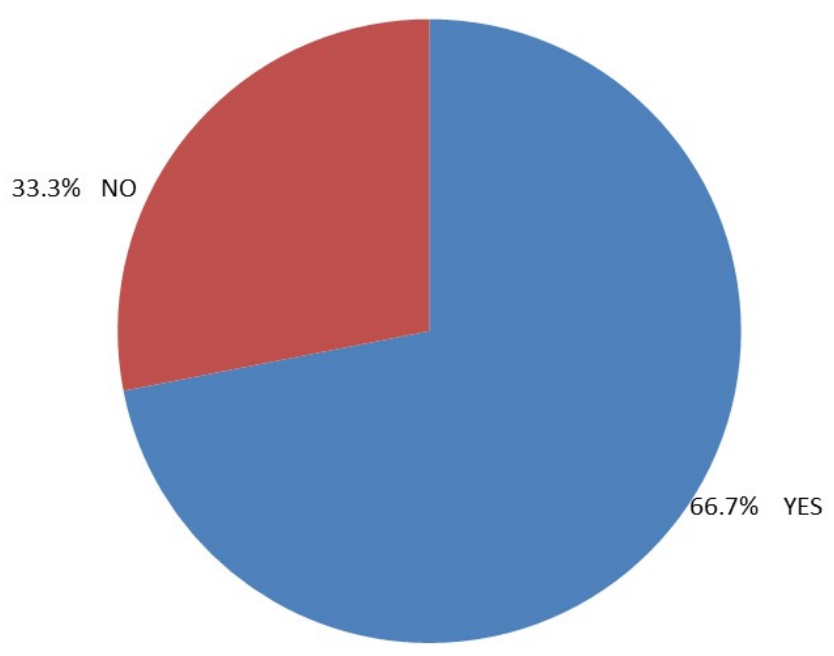

Chart 1. showing whether respondents got their AEDs regularly

check in the nearest health center.Table 5 Shows distance of respondents' homes from the nearest drug shops (n-30)

Half (50\%) of the respondents had their homes between 1 and 5 kilometers from the nearest drug shop, $43.7 \%$ were less than $1 \mathrm{~km}$ away from the nearest drug shop, and $6.3 \%$ were from 6 to 10 kilometers.

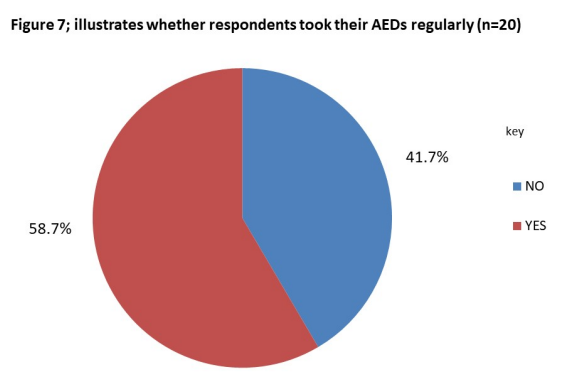

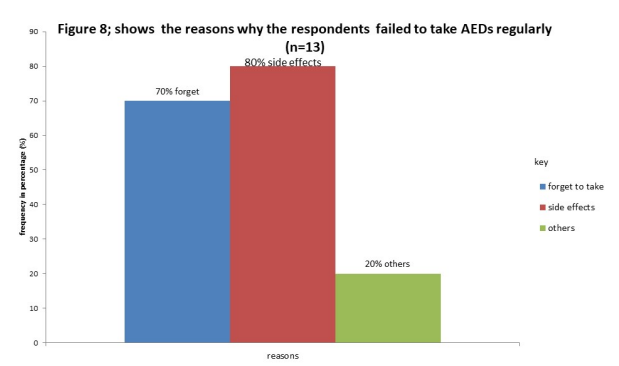

The majority, (70\%) just forget to take the AEDs, $(80 \%)$ did not take them because of the side effects associated with the AEDs.

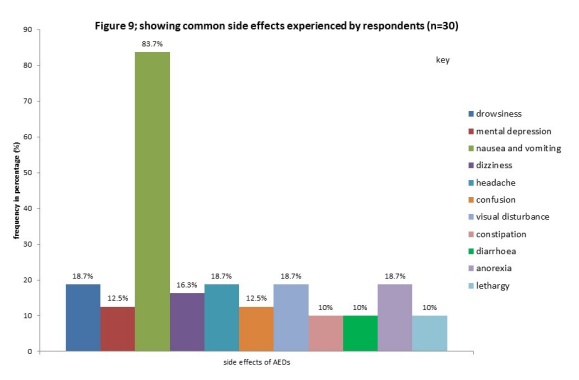

The total frequency was more than $100 \%$ because some respondents experienced more than one side effect. The majority of the respondents
$58.7 \%$ took their AEDs regularly while only $41.7 \%$ did not. 
Table 5. Shows distance of respondents' homes from the nearest drug shops

\begin{tabular}{lll}
\hline Distance & frequency & Percentage (\%) \\
Less than 1 kilometer & 14 & 43.7 \\
(1 to 5) kilometers & 16 & 50.0 \\
(6 to 10) kilometer & 2 & 6.3 \\
Total & $\mathbf{3 0}$ & $\mathbf{1 0 0}$ \\
\hline
\end{tabular}

$87.3 \%$, experienced nausea and vomiting compared to $10 \%$ who experienced constipation and another $10 \%$ who experienced diarrhea.

Traditional beliefs related factors.

Most of the respondents 33.3\%, felt ashamed, $13.3 \%$ felt nothing at all.
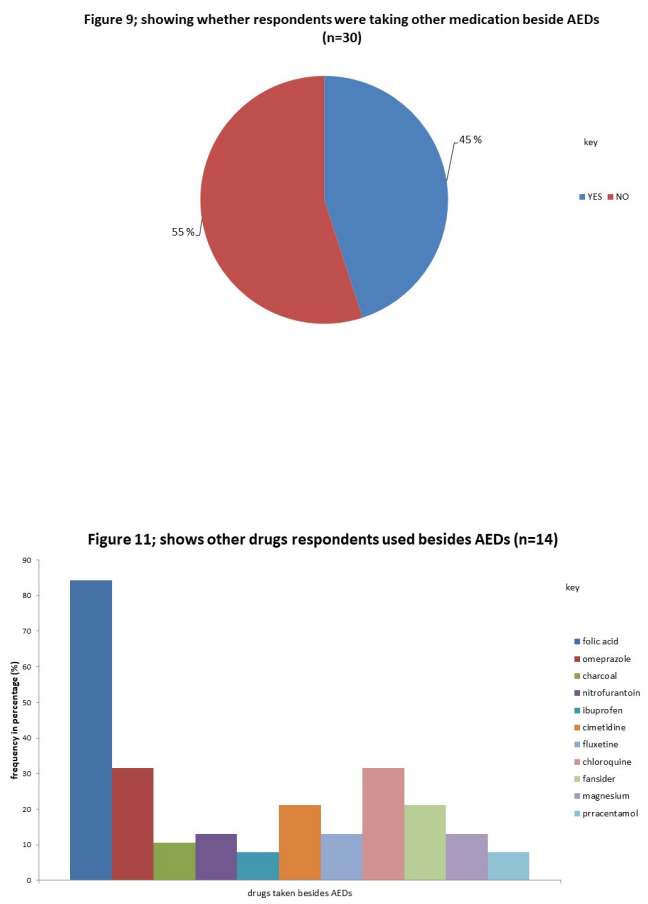

The percentage is more than $100 \%$ because respondents used more than one drug besides AEDs. Majority of the respondents $84.2 \%$ used folic acid.

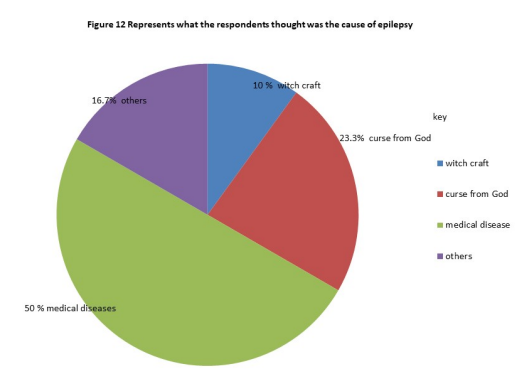

Half of the respondents believed that the condition was a medical disease (50\%), the rest of the respondents had numerous beliefs such as a curse from God (23.3\%), witchcraft (10\%), medical disease, while others (16.7\%) believed in causes such; born with. Table 7 Shows respondents' knowledge on what other people say is the mode of spread of epilepsy $n=30$;

Half of the respondents had knowledge on spread (50\%), sharing things with the epileptics, $10 \%$ other people believed that epilepsy is passed on from parents to their children.

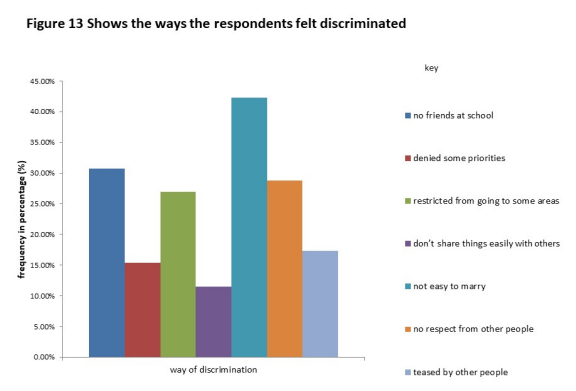

The percentage is more than $100 \%$ because some respondents mentioned more than one way of discrimination.

\section{Age and family -social factors}

\section{Age related factors}

Most of the respondents $50 \%$ were diagnosed with epilepsy at the age of 1-10 years compared to only $6.7 \%$ who were diagnosed with epilepsy at the age of 26 and above. 
Table 6. ; shows how the respondents felt when first diagnosed with epilepsy $(n=30)$.

\begin{tabular}{lll}
\hline How the respondents felt & frequency & Percentage (\%) \\
Ashamed & 10 & $33.3 \%$ \\
Angry & 6 & $20 \%$ \\
Surprised & 6 & $20 \%$ \\
Nothing & 4 & $13.3 \%$ \\
Others & 4 & $13.3 \%$ \\
Total & 30 & $100 \%$ \\
\hline
\end{tabular}

Table 7. Shows respondents' knowledge on what other people say is the mode of spread of epilepsy

\begin{tabular}{lll}
\hline What people say is the spread of epilepsy & frequency & Percentage (\%) \\
Through body contact with epileptic patients & 3 & $10 \%$ \\
Sharing things with epileptic patients & 3 & $10 \%$ \\
Passed from parents to their children & 15 & $50 \%$ \\
others & 9 & $30 \%$ \\
TOTAL & $\mathbf{3 0}$ & $\mathbf{1 0 0 \%}$ \\
\hline
\end{tabular}

Table 8. Shows the respondents age of diagnosis with epilepsy $(n=30)$

\begin{tabular}{lll}
\hline Age of diagnosis & frequency & Percentage (\%) \\
$1-10$ & 15 & 50 \\
$11-15$ & 8 & 26.7 \\
$15-25$ & 5 & 16.7 \\
26 and above & 2 & 6.7 \\
Total & $\mathbf{3 0}$ & $\mathbf{1 0 0}$ \\
\hline
\end{tabular}

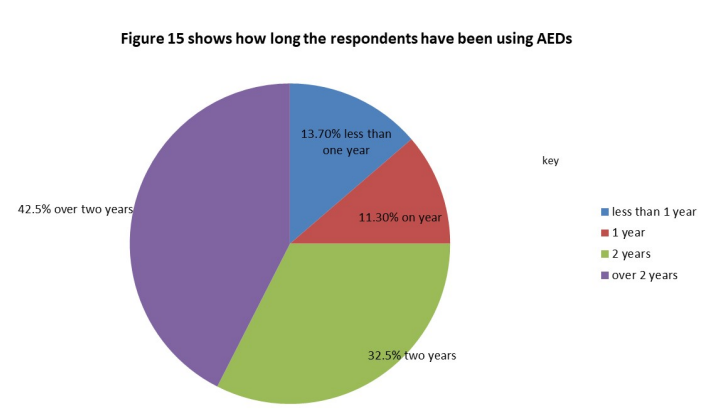

$42.5 \%$ had been on AEDs medication for over 2 years and $32.5 \%$ for at least 2 years.

\section{Family-social support}

An individual may be interested in taking up AEDs for medication, but without family-social support, even with mature understanding and good drug compliance, management of epilepsy becomes a problem. The results of family-social support areas are represented in the tables and figures below.
The respondents were asked if they were staying with someone or alone, it turned out that $93.3 \%$ of the respondents were staying with some and 6.7\% of the respondents stay alone, for those that were staying with someone, they were also asked who that person they were staying with was; the results were as on the table.

$92.9 \%$ of the respondents stayed with their relatives that included parents, aunts, and uncles and their partner, $7.1 \%$ stayed with their friends.

Usually come alone indicated $56.3 \%$ and $6.1 \%$ of the respondents usually came alone or at times came with someone, $36.7 \%$ who depended on the community members for a companion to the epileptic clinic.

Measures are taken to improve the management of epilepsy

The respondents and the focused group discussants were asked for the possible ways they thought, could be employed to improve the man- 
Table 9. Shows the persons with whom the respondents were staying, $(n=28)$

\begin{tabular}{lll}
\hline Person & frequency & Percentage (\%) \\
Grandparent & 7 & 25 \\
Aunt/uncle & 5 & 17.9 \\
Partner & 3 & 10.7 \\
Parents & 11 & 39.3 \\
Friend & 2 & 7.1 \\
Total & $\mathbf{2 8}$ & $\mathbf{1 0 0}$ \\
\hline
\end{tabular}

Table 10. Shows the reasons why the respondents had come alone to the clinic $(n=16)$

\begin{tabular}{lll}
\hline Reasons & Frequency & Percentage (\%) \\
Companion was busy at home & 3 & 18.8 \\
Companion is not at home & 3 & 18.8 \\
Usually come alone & 9 & 56.3 \\
No one in the community to come with at times could have some one & 1 & 6.1 \\
Total & $\mathbf{1 6}$ & $\mathbf{1 0 0}$ \\
\hline
\end{tabular}

agement of epilepsy in the SHC IV, the findings were presented in tables and graphs as follows;

First of all the respondents were asked if they faced any challenge,

$3.3 \%$ of the respondents said that they didn't face any challenge during their course of treatment while $96.7 \%$ of the respondents accepted that they faced some challenges during their treatment; the researcher then went on to ask them to list some of the challenges they faced, and the results were as in the graph below.

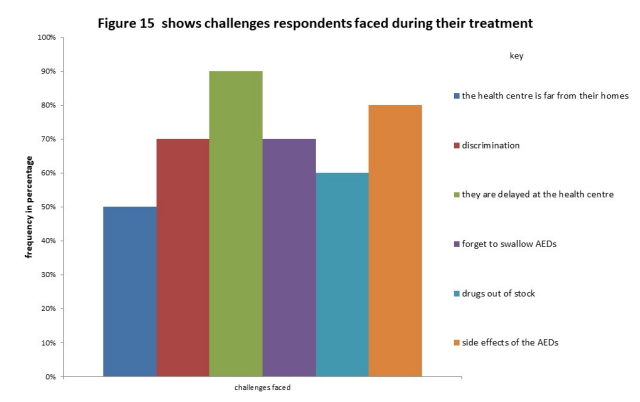

The frequency was more than $100 \%$ because some respondents faced more than one challenge.

The graph revealed that the respondents faced several challenges; this then prompted a question for the respondents' suggestions to the improvement of the management of epilepsy, what they suggested was plotted in a graph.

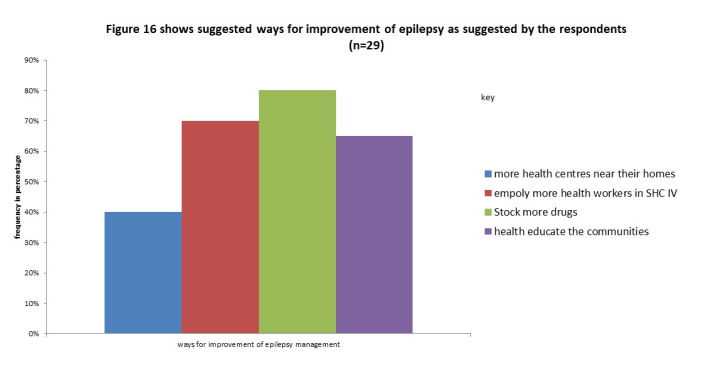

The percentage is more than $100 \%$ because the respondents made more than one suggestion, $40 \%$ of the respondents suggested that more health centers be built near their reach.

\section{Focused group discussion results;}

The first question for the group discussion was, what they thought was the community's perception about epilepsy

More than 100\% because some group members mentioned more than one perception. Some members, $60 \%$ said that people still perceived epilepsy as being contagious; another $60 \%$ said that people have accepted the disease and have come up for treatment, and $40 \%$ still believed that epilepsy is caused by witchcraft or a curse. 


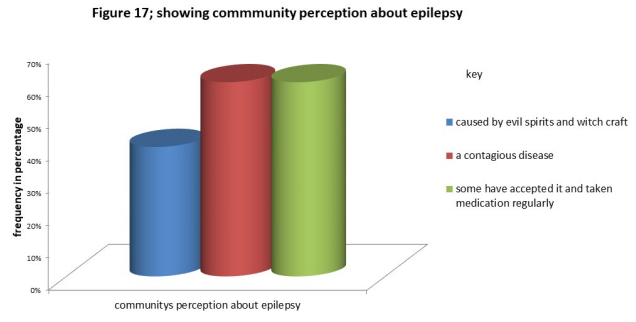

The majority $80 \%$ presented with complaints of long duration treatment of the condition as a difficulty, $50 \%$ of the respondents complained of long distance to the health center, and $70 \%$ of the respondents usually complained of discrimination.

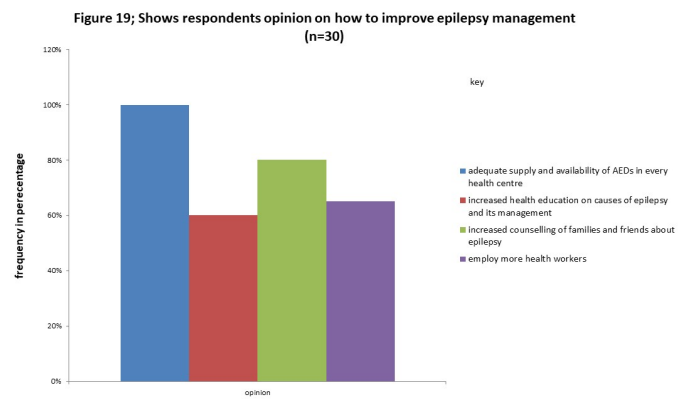

The percentage was more than $100 \%$ because the group members had more than one opinion. As shown above, $100 \%$ of the group suggested adequate supply and availability of the AEDs at every health center, $60 \%$ mentioned increased health education on epilepsy, $80 \%$ suggested increased counseling of families and friends about epilepsy, and $65 \%$ suggested that government employs more health workers to avert the heavy workload.

\section{DISCUSSION, CONCLUSION, AND RECOMMENDATIONS. 5 Discussions of the study findings}

The study aimed to find out the factors affecting the management of epilepsy amongst epileptic clients receiving treatment at SHC IV. The study set out to achieve the following objectives; to find out factors affecting management of epilepsy amongst epileptic clients of SHC IV and to identify measures to improve management of epilepsy amongst epileptic clients receiving treatment at SHC IV
Results revealed that, of the respondents who attended clinic day, $40 \%$ of the respondents were less than 19 years, 30\% were of the age between 20-29 years, $6.7 \%$ for the aged $40-49$ years and $6.7 \%$ were above 50 years, this suggested that most epileptic sufferers were below the age of 19 years.

Also of the 30 respondents that attended the clinic that day, $60 \%$ were males while $40 \%$ were females and this suggested that males were more affected than the females and this agrees with (Beghi, 2020) female adherence rate low than males.

Tribe majority of the respondents were Iteso, the other respondents were Kumam, and other tribes, for example, Basoga, Baganda, Karamojong, the Iteso were more in Serere probably because the district is located in the Teso region, where it is expected that the majority of the locals are Iteso.

A greater percentage, $66.7 \%$ were single, $13.3 \%$ divorced, $3.3 \%$ widowed, and $16.7 \%$ were married, this implied that most of the epileptic sufferers were not married, this was also evident after $42.3 \%$ of the respondents agreed that it was difficult for them to marry, to them this was some kind of discrimination as most people under looked them as potential partners.

Out of the 30 respondents that attended the clinic that day, $33.3 \%$ were Catholics, $40 \%$ protestants, $10 \%$ Muslims, and $16.7 \%$ others, others, in this case, included Pentecostals, orthodox, and pegans, this was suggestive that in Serere most of the population was protestants who were Christians and for strong faith in religion was making disease progress to the chronic stage, most patients had turned to tradition and religion, spiritual healing in respire for a cure. (Neil S.2O08)

40 Most of the respondents, $40 \%$ had no education, $33.3 \%$ had dropped out while in primary school, 20\% reached secondary education, and only $6.7 \%$ had tertiary education, this could be attributed to the forms of discrimination suffered by the epileptics as represented in figure 14 , where $50 \%$ of the respondents were peasants, $6.7 \%$ had salaried jobs, $20 \%$ were self-employed, and $23.3 \%$ were classified as others; that's to say had no jobs or were students, most epileptics had no salaried jobs most probably due to the nature of the disease, but can also be attributed to lack of formal education, as most of the respondents dropped out of school at preliminary levels agrees with literature said by (Epilepsy (Torch 2008) 
Figure 18 Shows problems respondents presented with on the clinic day

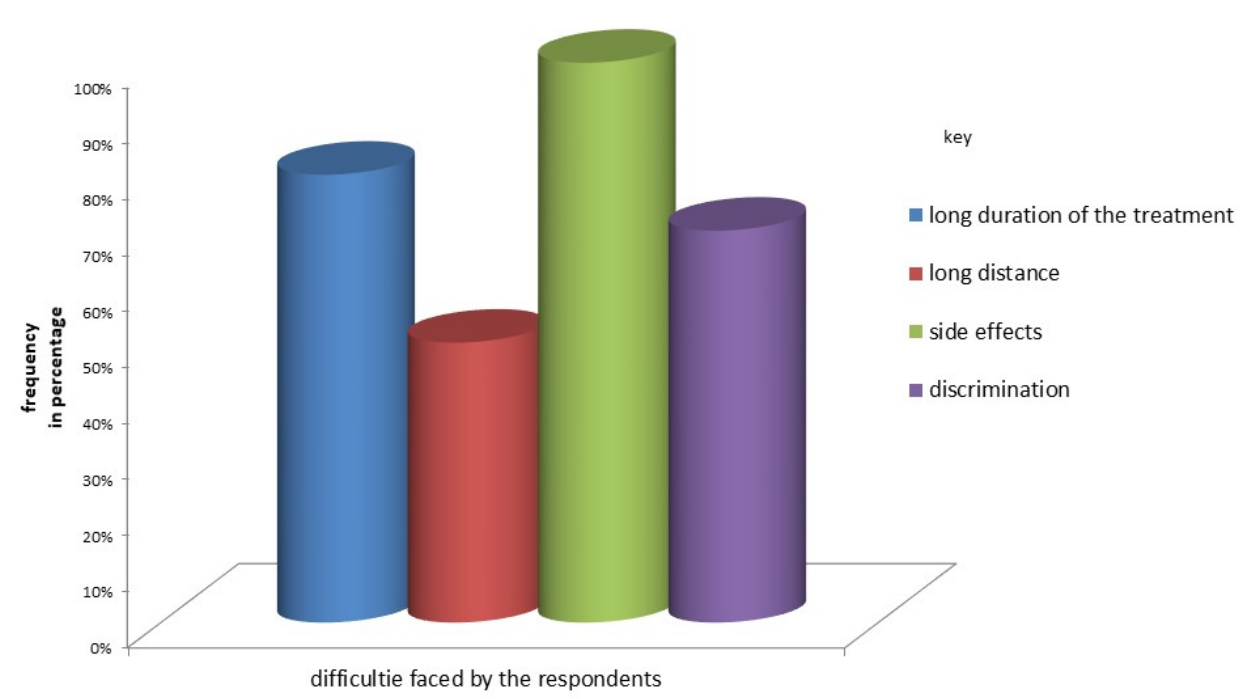

Chart 2.

Findings revealed that $66.7 \%$ of the respondents were getting their AEDs regularly, 33.3\% were not, when asked why they were not getting the AEDs regularly, $60 \%$ said that the drugs were often out of stock, and yet they were expensive to buy. Some of the respondents also missed clinic days, hence the irregular supply of AEDs, this same irregular supply affected the use of the drugs, and $58.7 \%$ agreed that they were not using their medicines regularly while $41.3 \%$ said that they used their AEDs regularly is by (WHO 2007) Research found reasons why the respondents did not use their AEDs regularly, and among the reason they given by; $80 \%$ of the respondents blamed side effects of the drugs such as nausea and vomiting, dizziness, drowsiness, mental confusion among others, $70 \%$ of the respondents forgot to take their AEDs at the required time, $20 \%$ of the respondents blamed other reasons such as fear of medicines, long duration of treatment, no one to remind them when to take the medication in time. (WHO 2007)

When asked what they do, when they run out of AEDs, the majority; $65.6 \%$ said that they usually wait for the next clinic day, a number of the respondents visit a nearby health center for a refill while others buy some from a drug shop, Odaga J (2008), however, noted that, in the districts of Nebbi and Arua, where a non-governmental organization operated a clinic that provided free AEDs to the epileptic clients, despite the free AEDs, clients kept on missing clinic days, hence poor adherence.

When asked about their distance from SHC IV, most of the respondents, $50 \%$ stay a distance of 1-5 kilometers away from the health center, $43.7 \%$ stay a distance not more than a kilometer away from the health center, and $6.3 \%$ stay within a distance of 6-10 kilometers from SHC IV, since most of the respondents stay a distance of about 1-50 kilometers, it, therefore, calls for an extra mile for the clients to get the drugs.

Also, $45 \%$ of the respondents consented to be using other medication besides AEDs, examples of other medications used were; Paracetamol tablets, charcoal tablets, amoxicillin capsules, metronidazole tablets, this gave a possibility of a drug reaction between AEDs and the other drugs used hence reducing the effectiveness of the AEDs,

The respondents were asked how they felt the very first time they were diagnosed with epilepsy, their response was; 33.3\% felt ashamed, 20\% felt angry, $20 \%$ felt suppressed, $13.3 \%$ felt nothing, others had mixed reactions, for example, confused, betrayed. Much as $50 \%$ of the respondents knew that epilepsy is a medical disease, $23.3 \%$ of the respondents still believe it to be a curse from God, some still believed that it could be caused by witchcraft while others still did understand the cause of the disease, this was consistent with a study conducted 
by Ismail, (2005) in the united kingdom, where correspondents thought that epilepsy was Gods punishment for certain sins committed and that epilepsy is contagious. (Ismail 2005).

The respondents also made it clear that much as most people in the community (50\%) know that epilepsy can be passed on from parents to their children, $10 \%$ of the respondents stilled believed that body contact spreads epilepsy, $10 \%$ also believed that sharing objects with epileptics spread epilepsy, while others did not know how epilepsy is spread. Since most of the respondents, $70 \%$, reported that they felt discriminated in the communities that they were in contact with, they then, were asked to list ways by which they felt discriminated; $30 \%$ reported that they found it difficult to make friends at school, $15 \%$ said that they were denied some privileges, $28 \%$ reported that they were denied from going to some areas, $11.5 \%$ reported that they are not allowed to share things with other people, $42.3 \%$ reported that it was not easy for them to marry, $22 \%$ reported that they were not respected by other people, lastly, 13\% reported to have been teased by other people. (Eadie, 2008)

Although epilepsy was prevalent in all age groups, most of the respondents 50\%, were diagnosed with epilepsy at an age less than 10 years, most of the respondents also revealed that they have used the AEDs for more than two years, and yet some of the respondents had complained that the long-life treatment was one of the challenges they faced, so there is a possibility that the lifelong treatment may lead to poor drug adherence, agrees

with (Eadie, 2008).

Most of the respondents were staying with someone, and $6.7 \%$ of the respondents reported to be staying alone. Most of the respondents were staying with their parents, grandparent, aunt/uncle, partners, and only $7.1 \%$ were staying with their friends.

More than half of the respondents came alone to the clinic, for those who came with someone, they were asked for the person with whom they came, most of them reported to have come with a family member, but $21.5 \%$ of the respondents came with a friend. Those who came alone were asked for reasons as to why they had done so, although some said that the persons who usually came with them to the clinic were either busy that day or were not at home that day, a majority openly said that they usually came alone to the clinic, this suggested low social support for the epileptic patients in their families, and community eventually, these findings were in line with the Epilepsy Torch (2008), that stated; people with epilepsy were being neglected by even their family members, as a result, most of the children with epilepsy dropped out of school.

The focused group members reported that although a majority of the community members know that epilepsy was a medical disease, a number also still believed that the disease is contagious and that it can be caused by witchcraft.

The other challenges the majority of the respondents and the focused group discussants pointed out were; long distances of the health center from their homes that at times makes them reach late to the clinic, discrimination, patients were often delayed by the busy health workers at the health center, the respondents also said that they at times forgot to swallow their AEDs, the AEDs were often out of stock, and a number of the respondents also complained of the side effects elicited by the AEDs, difficulty in the mobilization of the patients, poor drug adherence and compliance, and work overload were also raised by the health workers.

The respondents were then asked for what they thought could be employed to solve the above challenges, the majority suggested that Government; increases the stock of the AEDs at the health center, employ more health workers, such that they would get their health workers. Some also suggested that more health centers be built; this would in turn distribute the patients hence reducing the number of patients in SHC IV, a number of the respondents also believed that health education to the rest of the community would help reduce discrimination. Apart from increased counseling and health education to families and the community as a large, the focused group discussants agreed on the same ways to resolve the challenges just as mentioned patients.

\section{CONCLUSION}

Epilepsy management in SHC IV has always met several challenges, and for such challenges to be resolved, they should first be discovered, then possible measures are thought to solve them.

During the study, it was discovered that most patients were diagnosed with epilepsy at a young age of below 10 years and also that most males were affected than females.

Most of the respondents were Christian, with Protestants being the biggest number. It was also 
noted that most respondents were single (not married). The research further revealed that most of the respondents had no formal education, if any, a few ended in primary education; they, therefore, didn't have salaried jobs but rather were peasants.

The study revealed a lot of challenges that were faced by the patients, these challenges were; poor drug adherence and, evident by; irregular supply of AEDs, failure of the patients to take their drugs as prescribed due to either forgetting to swallow the drugs or deliberately refusing to swallow due to fear of side effects.

Discrimination by members of the community was confirmed by; $\frac{3}{4}$ of the respondents who consented that they felt discriminated, some community member's thoughts that; epilepsy was a result of accurse from God, witchcraft and that it is contagious, hence an imaginary boundary existed between the epilepsy sufferers and the non-epilepsy sufferers.

Poor social support took forms of; even though most respondents stay with their relatives, they always went alone to the clinic, most of the respondents dropped out of school and also failed to marry.

Most respondents stay far from the health center and also patients always outnumber the health workers at the health center.

Some of the suggested ways of improving the management of epilepsy as suggested by the respondents and the focused group discussants were; health education and counseling of the entire community, stocking of enough AEDs in the health center, employing more health workers, and probably build more health centers.

\section{RECOMMENDATIONS}

The district health office of Serere, nonGovernmental organizations, ministry of health or well-wishers, could base on this research or conduct a similar study, and then take appropriate actions necessary to improve management of epilepsy in SHC IV.

\section{IMPLICATIONS TO THE NURSING PROFESSION}

It's an eye-opener to the nurses and administrators in the nursing profession particularly those in the management of epilepsy, on what needs to be done to improve the management of epilepsy.

Other students can use this as a reference for carrying out further researches on similar or related topics.
The study will display the major challenges faced by epilepsy suffers and possible ways to improve their management; to the limelight such that appropriate action is thought by the stakeholders.

\section{ACKNOWLEDGEMENT}

I would like to, first of all, thank the almighty God, the Ministry of Education and sports, ministry of health of Uganda for having designed a diploma in Comprehensive Nursing course as a step towards strengthening the health systems practice.

Special thanks go to my dedicated supervisor, Mr. Wakaato Marc Paul for his technical support, parental guidance, and constant encouragement, and his acceptance to supervise my research despite his busy schedule.

Furthermore, I would like to extend my honor to the principal, entire staff, both teaching and nonteaching, and students of Soroti School of Registered Comprehensive Nursing for their great contributions to the activities of the broad-based course.

My heartfelt appreciation goes to my family; my mother Mrs. Amongin Merab, brother Emmanuel, sisters; Suzan, Deborah, Monica, and Eunice, my wife Eve, and daughter Linda Keira. Friends; Tomas, Simon, Paul, mark, George, Ambrose, Barbara, Charles, Jorem, and Harriet, for their constant encouragement and emotional support offered during my study time.

I also would like to thank Okwaro j. who lent me his laptop thus enabling me to get this work typed and printed in time. Finally, I would to highly appreciate the tireless efforts of all those who participated in one way or the other during my struggle for the success of this report.

May the almighty God bless you wholeheartedly.

\section{LIST OF ABBREVIATIONS IACRONYMS}

AEDs Anti-epileptic drugs

AHRQ Agency for health care Research and Quality

PLWE People living with Epilepsy

SHC IV Serere Health centre Four

USA United States of American

WHO World health Organization 


\section{A References:}

1). Beghi E. (2020) The Epidemiology of Epilepsy. ht tps://doi.org/10.1159/000503831

2). Epilepsy Foundation of America (2000).Epilepsy: questions and answers about seizure disorders. Landover, MD.

3). Inside. (2013). Overcoming the challenges of epilepsy. https://inside.Ihsc.on.ca/article/summer2013/overcoming-epilepsy.

4). Ismail, H., Wright, J., Rhodes, P., \& Small, N. (2005). Religious beliefs about causes and treatment of epilepsy. The British journal of general practice : the journal of the Royal College of General Practitioners, 55(510), 26-31.

5). John Odaga, Luigi Ciccio and Everd B. Maniple (2008), Overcome Barriers to Anti-Epileptic treatment: A life time sentence? Health policy and Development Journal, vol. 6, No. 1, April, 2008,pp.54-65 Uganda Martyrs university, P.o.Box 5498 Kampala,

6) L. James Willmore (2007) Epilepsia Texas comprehensive Epilepsy Program, Department of Neurology, university of Texas medical school, Houston, Texas, U.S.A. volume 37 issue s6, pp s23 -s33 published online: Nov 2007 (c2009 International League Against Epilepsyhttps://doi.org/10.1111/j.1 528-1157.1996.tb06036.x PMid:8941039

7). Patty (2013). Epilepsy Foundation Communications. Wednesday, July 21, 2021. https://www.epi lepsy.com/learn/about-epilepsy-basics

8). Reuber M, Gore J, Wolstenhome Jonas P, Frankson C, Murray C, Styring L. (2007): Examining a community model of epilepsy care for people with disabilities. Sheffield teaching hospitals NHS Trust, Department of neurology.https://doi.org/10.1016/j. seizure.2007.07.004 PMid:17719802 